$\mathrm{DE}$

M E D I C I N A

T R O P I C A L

$\mathrm{DE}$

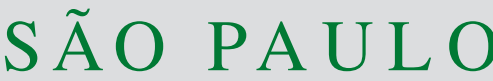

JOURNAL OF THE SÃO PAULO INSTITUTE OF TROPICAL MEDICINE

(1)Universidade Federal de Santa Maria. Departamento de Microbiologia e Parasitologia, Santa Maria, Rio Grande do Sul, Brazil

(2)Universidade Federal de Santa Maria, Departamento de Farmácia Industrial, Santa Maria, Rio Grande do Sul, Brazil

(3) Universidade Federal do Rio Grande do Sul, Programa de Pós-Graduação em Ciências Biológicas: Farmacologia e Terapêutica, Porto Alegre, Rio Grande do Sul, Brazil

(4) Universidade Federal de Santa Maria, Departamento de Química Orgânica, Santa Maria, Rio Grande do Sul, Brazil.

(5)Centro Universitário Franciscano, Laboratório de Farmacologia, Toxicologia e Botânica, Santa Maria, Rio Grande do Sul, Brazil

Correspondence to: Mario Luiz de la Rue Universidade Federal de Santa Maria, Departamento de Microbiologia e Parasitologia, Avenida Roraima, 1000 Campus Universitário, Prédio 20, Sala 4226, CEP 97105-970, Santa Maria, RS, Brazil.

E-mail: mldelarue@ hotmail.com

Received: 2 December 2015

Accepted: 22 February 2017

\section{In vitro effects of Blepharocalyx salicifolius (H.B.K.) O. Berg on the viability of Echinococcus ortleppi protoscoleces}

Charlise Bolson Noal', Danieli Urach Monteiro', Thiele Faccim de Brum², Jessica Emmanouilidis ${ }^{1}$, Regis Adriel Zanette ${ }^{3}$, Ademir Farias Morel $^{4}$, Eliza Beti de Cassia Stefanon ${ }^{5}$, Marina Frosi ${ }^{5}$, Mario Luiz de la Rue ${ }^{1}$

\section{ABSTRACT}

Scolicidal agents are important in the treatment of cystic echinococcosis. This study evaluated the scolicidal activity of the plant Blepharocalyx salicifolius (H.B.K.) Berg against Echinococcus ortleppi protoscoleces. The parasite species was identified by amplifying a fragment of the gene cytochrome $c$ oxidase subunit 1 (COX 1). B. salicifolius crude extract at concentrations of 100, 200, 300 and $400 \mathrm{mg} / \mathrm{mL}$ was analyzed at different times $(5,10$, $15,30,45$ and $60 \mathrm{~min}$ ). N-butanol and ethyl acetate fractions (100 and $200 \mathrm{mg} / \mathrm{mL}$ ) were also analyzed at 5, 10, 15 and $30 \mathrm{~min}$. Both fractions showed $100 \%$ scolicidal activity at the concentration of $200 \mathrm{mg} / \mathrm{mL}$ at $5 \mathrm{~min}$. Gallic acid, identified as the major compound of the ethyl acetate fraction- was responsible for the observed scolicidal activity. The results showed that crude extract and fractions of $B$. salicifolius have scolicidal effect against E. ortleppi protoscoleces.

KEYWORDS: Echinococcus ortleppi. Protoscolicidal. Scolicidal agent. Gallic acid.

\section{INTRODUCTION}

Echinococcus ortleppi is one of the species of Echinococcus spp. found in Southern Brazil ${ }^{1}$ and in some regions of Europe, Africa, South Asia and the Americas $^{2}$. There are also reports of E. ortleppi causing cystic echinococcosis (CE) in humans $\mathbf{s}^{3,4,5}$.

Until the 80's, surgery was the only option for treatment of CE. Subsequently, chemotherapy with benzimidazole compounds and, later, treatment by PAIR (puncture, aspiration, injection and reaspiration) was introduced ${ }^{6}$. One of the major surgical complications of $\mathrm{CE}$ is recurrence, after the primary hydatid disease treatment. Dissemination of protoscolex-rich fluid during surgery is a major cause of recurrence and multiple secondary $\mathrm{CE}^{7}$. The use of an effective scolicidal solution during the surgical procedure is an important tool in CE treatment, and this can significantly reduce the rate of disease recurrence ${ }^{8}$.

Among the countless plant species of medicinal interest, Blepharocalyx salicifolius (H.B.K.) O. Berg (Myrtaceae) has been used in the treatment of leukorrhea, diarrhea, digestive problems and to treat cystitis and urethritis ${ }^{9}$. In folk medicine, B. salicifolius is known as "murta" and is distributed throughout South America, from Ecuador to Uruguay ${ }^{10}$. In vitro antiparasitic activity of $B$. salicifolius extract has been reported against Leishmania amazonensis ${ }^{11}$. Therefore, due to the fact that scolicidal agents are limited and may cause side effects that can be harmful to human health, the aims of this study were to evaluate the scolicidal 
action of B. salicifolius on protoscoleces of E. ortleppi and to determine the compounds present in the extract that are likely to be responsible for such action.

\section{MATERIAL AND METHODS}

\section{Preparation of plant material}

\section{Crude extract}

B. salicifolius leaves were collected in the city of Nova Prata, Rio Grande do Sul State, Brazil, in November 2011. A fertile branch was identified and deposited at the Herbarium of Universidade Federal de Santa Maria (catalog number SMDB 13.515). The leaves were dried in a laboratory oven, with air circulation, at $40^{\circ} \mathrm{C}$ for $72 \mathrm{~h}$, and then ground in a Wiley knife mill. Plant material was submitted to an aqueous extraction for $30 \mathrm{~min}$ at $70{ }^{\circ} \mathrm{C}$. Thereafter, the extract was stored in Petri dishes and transferred into an oven with air circulation, at $42{ }^{\circ} \mathrm{C}$ for $48 \mathrm{~h}$. The crude extract consisted of plate scrapings ${ }^{12}$.

\section{Fractions}

For obtaining the component fractions, a crude extract portion was dissolved in $50 \mathrm{~mL}$ of distilled water. Initially, ethyl acetate (EtOAc) fraction was extracted $(3 \times 20 \mathrm{~mL})$ in a separatory funnel, and the solvent was dried through evaporation until the total dryness of the EtOAc fraction. The same procedure was carried out to obtain the n-butanol $(\mathrm{BuOH})$ fraction. The remaining aqueous extract was lyophilized yielding the aqueous fraction.

\section{HPLC-DAD quantitative analysis of rutin and gallic acid}

Reverse phase chromatography analyses were carried out under gradient conditions using a Techno Sciences C-18 column $(4.6 \mathrm{~mm} \times 250 \mathrm{~mm})$. The flow rate was $0.6 \mathrm{~mL} / \mathrm{min}$, the injection volume was $40 \mu \mathrm{L}$ and the gradient elution was conducted according to Boligon et al. ${ }^{13}$, with minor modifications. Mobile phase consists of water containing $2 \%$ acetic acid (solvent $\mathrm{A}$ ) and acetonitrile (solvent $\mathrm{B}$ ).

In an attempt to identify the compounds present in the plant under study, tests were performed with different commercial standards, where the presence of rutin and gallic acid was detected. The ultraviolet (UV) absorption spectra of the standards rutin (Sigma-Aldrich, Brazil) and gallic acid (Vetec Química, Brazil) and of the samples were recorded in the range of 230-400 $\mathrm{nm}$. Samples, standard solutions and the mobile phase were degassed and filtered through a $0.45 \mu \mathrm{m}$ membrane filter (Merck-Millipore, Billerica, MA, USA). Chromatographic operations were carried out at room temperature and in triplicate. Identification of the compounds was done by comparison of their retention times and UV absorption spectrum with the respective standards. The substance contents were obtained for the calibration curves (gallic acid, $\mathrm{y}=71293 \mathrm{x}-76386, \mathrm{r}=0.9958$; rutin, $\mathrm{y}=75045 \mathrm{x}-18282, \mathrm{r}=0.9929)$.

\section{Collection of protoscoleces}

Hydatid cysts from lungs of naturally infected bovines were collected in a slaughterhouse in the central region of Rio Grande do Sul State. The hydatid cyst fluid was aseptically transferred to glass cylinders. After $30 \mathrm{~min}$, protoscoleces were deposited on the bottom. The supernatant was then removed and the protoscoleces were washed three times in $0.9 \%$ saline for later use. Protoscoleces viability was assessed using $0.1 \% \operatorname{eosin}^{14}$. The percentage considered suitable for the development of our experimental test was of at least $98 \%$ of viability.

\section{Molecular analysis}

DNA extraction was performed using an aliquot of the liquid containing hydatid protoscoleces, using a commercial kit (QIAamp tissue, QIAGEN Inc., Chatsworth, CA), according to the manufacturer's instructions. Polymerase chain reaction (PCR) was performed using a pair of primers (5'TTTTTTGGGCATCCTGAGGTTTAT3' and 5'TAAAGAAAGAACATAATGAAA ATG 3') to amplify a fragment of COX-I gene ${ }^{15}$, with modifications. The reactions were carried out in a thermocycler model PTC-100 ${ }^{\mathrm{TM}}$ (MJ Research, Inc.). To detect the pattern of bands, electrophoresis was performed on $1 \%$ ethidium bromide-stained agarose gel and visualized under UV light. The similarity of DNA samples sequenced with the COX-I gene was carried out by using the BLAST program (http://www.ncbi.nlm.nih.gov).

\section{Scolicidal assay}

For analysis of the scolicidal effect, $100 \mu \mathrm{L}$ of hydatid fluid containing protoscoleces were added to $100 \mu \mathrm{L}$ of each of the agents tested (crude extract, fractions and standards), along with $200 \mu \mathrm{L}$ of $0.1 \%$ eosin, yielding a final volume of $400 \mu \mathrm{L}$ for each analysis. Distilled water was used as a dilution vehicle for the agents. The negative control group received $100 \mu \mathrm{L}$ of hydatid fluid, $100 \mu \mathrm{L}$ of distilled water and $200 \mu \mathrm{L}$ of $0.1 \%$ eosin.

Crude extract and fractions of $B$. salicifolius; gallic acid and rutin standards

A crude extract was tested at concentrations of 100 , 200,300 and $400 \mathrm{mg} / \mathrm{mL}$ at 5, 10, 15, 30, 45 and $60 \mathrm{~min}$, at room temperature. $\mathrm{BuOH}$ and EtOAc fractions were analyzed at 100 and $200 \mathrm{mg} / \mathrm{mL}$ at 5, 10, 15 and $30 \mathrm{~min}$. Gallic acid and rutin standards were evaluated in order 
to find the lowest concentration and the lowest time that showed full scolicidal action. The negative control group was also assessed in the same conditions.

\section{Viability test}

In the present study, $0.1 \%$ eosin was used to check the viability of the protoscoleces. The viability was evaluated by the same optical microscope, at different times and concentrations described, observing motility and eosin staining, counting 100 protoscoleces at each evaluation. The protoscoleces were considered viable when they remained unstained $^{14,16}$.

\section{Statistical analysis}

Data were plotted using the Kaplan-Meier analysis, and differences in protoscoleces viability were analyzed by the log-rank test using GraphPad software (version 6.1., La Jolla, CA). Each experiment was performed in triplicate. A -p-value of $<0.05$ was considered statistically significant.

\section{RESULTS}

The identification and quantification of the compounds present in EtOAc and $\mathrm{BuOH}$ fractions of B. salicifolius are shown in Table 1. Gallic acid and rutin were not found in the crude extract.

Table 1 - HPLC/DAD determination of gallic acid and rutin in fractions obtained from $B$. salicifolius leaves

\begin{tabular}{lcc}
\hline \multirow{2}{*}{ Fractions } & \multicolumn{2}{c}{ Compounds $(\mathrm{mg} / \mathrm{g}$ of dry fraction) } \\
\cline { 2 - 3 } & Gallic acid & Rutin \\
\hline Crude extract & - & - \\
EtOAc & $91.3 \pm 0.7$ & $95.2 \pm 0.88$ \\
$\mathrm{BuOH}$ & $66.22 \pm 1.09$ & $65.26 \pm 0.93$ \\
\hline
\end{tabular}

Not detected (-). Values are expressed as the mean $\pm \operatorname{SD}(n=3)$.
The protoscoleces obtained in this study were molecularly identified as the E. ortleppi species. Figure 1 shows the in vitro effects of $B$. salicifolius on the viability of E. ortleppi protoscoleces exposed to different concentrations of the plant leaf crude extract. It is noteworthy that $B$. salicifolius extract showed dose-dependent and time-dependent effects against the protoscoleces. The negative control group did not present changes throughout the experimental time, maintaining a viability of $98 \%$.

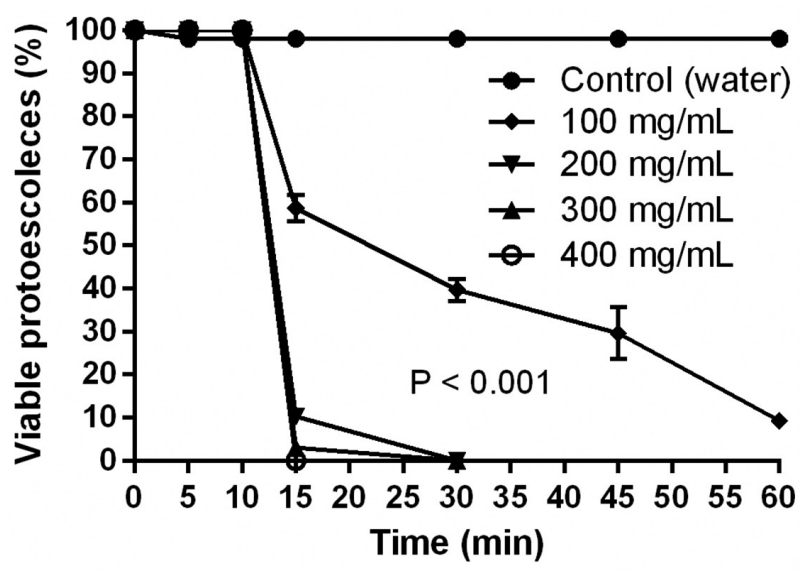

Figure 1 - Percentage viability of E. ortleppi protoscoleces exposed to different concentrations of $B$. salicifolius leaf crude extract. Data are means \pm SD of triplicate samples. $P<0.001$ in comparison to the control group (water)

The viability assays for $\mathrm{BuOH}$ and EtOAc fractions are shown in Figure 2. The HPLC/DAD analysis revealed two distinct patterns in the EtOAc and $\mathrm{BuOH}$ fractions of B. salicifolius: gallic acid and rutin. The assay performed with gallic acid standard showed $100 \%$ scolicidal activity at $5 \mathrm{~min}$. at the concentration of $25 \mathrm{mg} / \mathrm{mL}$. Conversely, rutin standard did not present any scolicidal action in this study.

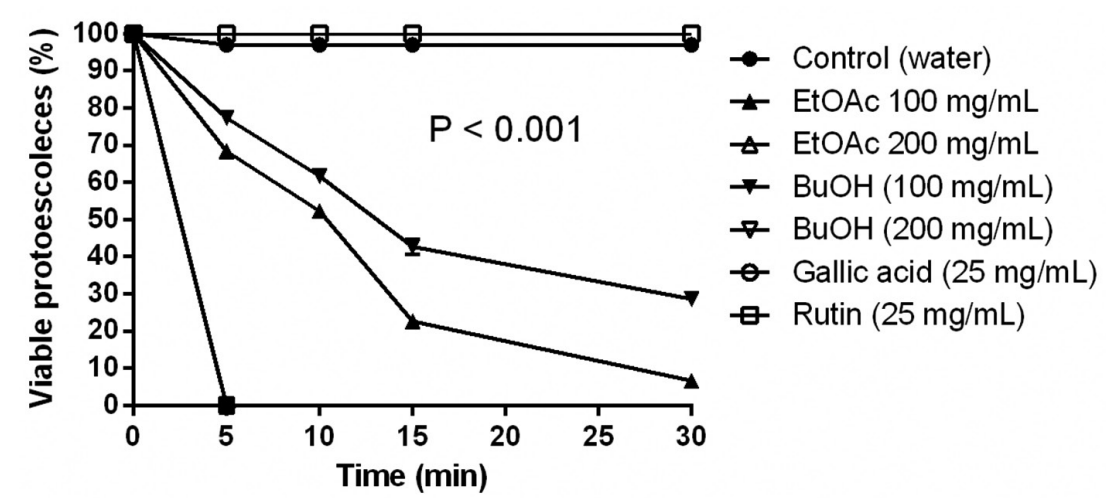

Figure 2 - Percentage viability of E. ortleppiprotoscoleces exposed to different concentrations of ethyl acetate (EtOAc) and n-butanol $(\mathrm{BuOH})$ fractions, gallic acid and rutin. Data are means \pm SD of triplicate samples. Values of $\mathrm{p}-<0.001$ in comparison to the control group (water), except for rutin ( $p>0.05)$. EtOAc $(200 \mathrm{mg} / \mathrm{mL}), \mathrm{BuOH}(200 \mathrm{mg} / \mathrm{mL})$ and gallic acid curves are overlapped 


\section{DISCUSSION}

The identification of E. ortleppi in this study corroborates previous studies that have reported the presence of this Echinococcus species in cattle raised in Rio Grande do Sul State ${ }^{1,17}$. According to Nakao et al. ${ }^{18}$, this parasite is highly fertile and prolific in cattle. Importantly, a human case of $\mathrm{CE}$ caused by E. ortleppi has been previously reported in the studied area ${ }^{5}$. In this study, the tests with $B$. salicifolius showed highly significant scolicidal effects. According to the results obtained in the tests, $100 \%$ scolicidal activity using the crude extract was obtained at the concentration of $400 \mathrm{mg} / \mathrm{mL}$ at $15 \mathrm{~min}$., which is comparable to the scolicidal action of hypertonic saline (at 20\% during $15 \mathrm{~min}$ ) and with the action of ethyl alcohol (at 95\% during $15 \mathrm{~min})^{19}$. In line with these results, $\mathrm{BuOH}$ and EtOAc fractions reached $100 \%$ scolicidal effect at $200 \mathrm{mg} / \mathrm{mL}$ at $5 \mathrm{~min}$, presenting the same results regarding the action and time-exposure reported in another study using $20 \%$ sodium chloride ${ }^{20}$. These results were able to validate the methodology used in this study and, most importantly, confirmed the scolicidal action of the plant evaluated in our experiment.

The analysis of the compounds present in $B$. salicifolius fractions identified gallic acid, which was found in higher proportion in EtOAc when compared to $\mathrm{BuOH}$ fraction. The greater scolicidal action of EtOAc when compared to $\mathrm{BuOH}$ fraction confirmed the gallic acid as the scolicidal agent of the extract. Indeed, the result obtained with the gallic acid standard, which showed $100 \%$ scolicidal activity at the concentration of $25 \mathrm{mg} / \mathrm{mL}$ at $5 \mathrm{~min}$, was considered ideal, demonstrating effectiveness against $E$. ortleppi. Studies with gallic acid and some of its derivatives have already been reported as effective against Trypanosoma cruzi $^{21}$ and T. brucei brucei ${ }^{22}$ in vitro. The mechanisms determining the action of gallic acid that leads to death of these parasites have not been completely elucidated, but it is reported that the presence and the size of the alkyl chain in gallic acid can be related to lipid solubility characteristics and, consequently, it can provide different degrees of cell permeability. These findings may explain a likely mechanism of action of gallic acid that leads to protoscoleces death. Importantly, B. salicifolius raw extract might have other compounds with scolicidal action that have not been determined yet.

Considering the need for new perspectives for the treatment of $\mathrm{CE}$, this study identified satisfactory scolicidal actions of B. salicifolius leaf crude extract, of EtOAc and $\mathrm{BuOH}$ fractions and of gallic acid, at all concentrations tested, against E. ortleppi protoscoleces. Further studies are necessary to investigate the mechanism of action and the potential scolicidal effects of $B$. salicifolius in vivo.

\section{REFERENCES}

1. Balbinotti H, Santos GB, Badaraco J, Arend AC, Graichen DA, Haag KL, et al. Echinococcus ortleppi (G5) and Echinococcus granulosus sensu stricto (G1) loads in cattle from Southern Brazil. Vet Parasitol. 2012;188:255-60.

2. Dinkel A, Njoroge EM, Zimmermann A, Wälz M, Zeyhle E, Elmahdi IE, et al. A PCR system for detection of species and genotypes of the Echinococcus granulosus - complex, with reference to the epidemiological situation in eastern Africa. Int J Parasitol. 2004;34:645-53.

3. Maravilla P, Andrew Thompson RC, Palacios-Ruiz JA, Estcourt A, Ramirez-Solis E, Mondragon-de-la-Peña C, et al. Echinococcus granulosus cattle strain identification in an autochthonous case of cystic echinococcosis in central Mexico. Acta Trop. 2004;92:231-6.

4. Sharma M, Sehgal R, Fomda BA, Malhotra A, Malla N. Molecular characterization of Echinococcus granulosus cysts in north Indian patients: identification of G1, G3, G5 and G6 genotypes. PLoS Negl Trop Dis. 2013;7:e2262.

5. De la Rue ML, Takano K, Brochado J, Costa CV, Soares AG, Yamano K, et al. Infection of humans and animals with Echinococcus granulosus (G1 and G3 strains) and E. ortleppi in Southern Brazil. Vet Parasitol. 2011;177: 97-103.

6. Moro PL, Schantz PM. Echinococcosis: historical landmarks and progress in research and control. Ann Trop Med Parasitol. 2006;100:703-14.

7. Moro P, Schantz PM. Echinococcosis: a review. Int J Infect Dis. 2009;13:125-33

8. Wen H, New RRC, Craig PS. Diagnosis and treatment of human hydatidosis. Br J Clin Pharmacol. 1993;35:565-74.

9. Alice CB, Vargas VMF, Silva GAAB, De Siqueira NCS, Schapoval EES, Gleye J, et al. Screening of plants used in south Brazilian folk medicine. J Ethnopharmacol. 1991;35:165-71.

10. Limberger RP, Sobral MEG, Zuanazzi JAS, Moreno PRH, Schapoval EES, Henriques AT. Biological activities and essential oil composition of leaves of Blepharocalyx salicifolius. Pharm Biol. 2001;39:308-11.

11. Siqueira EP, Souza-Fagundes EM, Sobral MEG, Alves TMA, Rabello A, Zani CL. Leishmanicidal activities of the extract from Blepharocalyx salicifolius (Kunth) O. Berg, Myrtaceae. Rev Bras Pharmacogn. 2010;20:416-21.

12. Palmeiro NMS, Almeida CE, Ghedini PC, Goulart LS. Evaluation of the acute toxicity of the aqueous crude extract of leaves of Plantago australis. Rev Bras Toxicol. 2002;15:15-7.

13. Boligon AA, Brum TF, Frolhich JK, Froeder ALF, Athayde ML. HPLC/DAD profile and determination of total phenolics, flavonoids, tannins and alkaloids contents of Scutia buxifolia Reissek stem bark. Res J Phytochem. 2012;6:84-91.

14. Moazeni M, Saharkhiz MJ, Hoseini AA, Alavi AM. In vitro scolicidal effect of Satureja khuzistanica (Jamzad) essential 
oil. Asia Pac J Trop Biomed. 2012;8:616-20.

15. Bowles J, Blair D, McManus DP. Genetic variants within the genus Echinococcus identified by mitochondrial DNA sequencing. Mol Biochem Parasitol. 1992;54:165-73.

16. Yones D, Taher GA, Ibraheim ZZ. In vitro effects of some herbs used in Egyptian traditional medicine on viability of protoscolices of hydatid cysts. Korean J Parasitol. 2011;49:25563.

17. De la Rue ML, Dinkel A, Mackenstedt U, Romig T. New data on Echinococcus spp. in Southern Brazil. Rev Inst Med Trop Sao Paulo. 2006;48:103-4.

18. Nakao M, Lavikainen A, Yanagida T, Ito A. Phylogenetic systematics of the genus Echinococcus (Cestoda: Taeniidae). Int J Parasitol. 2013;43:1017-29.
19. Moazeni M, Nazer A. In vitro effectiveness of garlic (Allium sativum) extract on scolices of hydatid cyst. World J Surg. 2010;34:2677-81.

20. Ghazanfari T, Hassan ZM, Yaraii R. The in vitro effects of aqueous garlic extract and garlic fractions on the growth of Leishmania major. Kowsar Med J. 1998;5:117-22.

21. Letelier ME, Rodriguez E, Walace A, Lorca M, Repetto Y, Morello A, et al. Trypanosoma cruzi: a possible control of transfusion-induced Chagas' disease by phenolic antioxidants. Exp Parasitol. 1990;71:357-63.

22. Koide T, Nose M, Inoue M, Ogihara Y, Yabu Y, Ohta N. Trypanocidal effects of gallic acid and related compounds. Plant Med. 1998;64:27-30. 